\title{
New Electrodes Based on Garlic for the Inhibition of the Free Radicals Effects
}

Saâdane H, Ennachete M, Moutcine A, Qouatli EIS and Chtaini A*

Equipe d'Electrochimie Moléculaire et Matériaux Inorganiques, Faculté des Sciences et Techniques de Béni Mellal, Université Sultan Moulay Slimane, Morocco

\begin{abstract}
A new electrode based on garlic is prepared to inhibit the effect of oxidative stress, often linked to the presence of an excess of free radicals. The electrode paste was prepared as a mixture of finely powdered of garlic together with graphite powder. The influence of variables such as the garlic loading and free radicals concentration was tested by square wave voltammetry (SWV), cyclic voltammetry (CV) and electrochemical impedance spectroscopy (EIS). The obtained results were found in good correlation with garlic reputation.
\end{abstract}

Keywords: Garlic; Oxidative stress; SWV; CV; EIS; Modified electrodes

\section{Introduction}

Oxidative stress is defined as an imbalance between the production of free radicals and the ability of the body to counteract or detoxify their harmful effects through neutralization by antioxidants. Free radicals play an essential role in the biochemical processes of living beings. They are continuously produced by the body's normal use of oxygen such as respiration and some cell mediated immune function. At high concentrations, free radicals generate oxidative stress, a deleterious process that can damage all cell structures [1-8]. Oxidative stress can develop of chronic and degenerative diseases such as cancer, arthritis, aging, autoimmune disorders, cardiovascular and neurodegenerative diseases. Antioxidant compounds in food are found to have a health protecting factor. Primary sources of naturally occurring antioxidants are whole grains, fruits and vegetables. Garlic (Allium sativum) is an herb. It is best known as a flavoring for food [9]. But over the years, garlic has been used as a medicine to prevent or treat a wide range of diseases and conditions. Garlic consists of more than 250 genera and 3700 species. The potential antioxidant properties of garlic are related to its phenolic and flavonoid fractions [10].

Several amperometric biosensors have already been proposed for antioxidant capacity determination [11-14]. Most of them are based on the amperometric detection of $\mathrm{H}_{2} \mathrm{O}_{2}$, resulting from the catalyzed dismutation of superoxide radicals $\left(\mathrm{O}_{2}^{-}\right)$in presence of superoxide dismutase. In this work we prepared and characterized the garlic modified carbon-paste electrode, which successfully exploits the favorable mechanical and electrochemical properties of carbon-paste electrodes. Our work develops the electrochemical technology of the inhibition of effects of free radicals.

\section{Experimental}

\section{Instrumentation and software}

Square-wave voltammetry was performed with a voltalab potentiostat (model PGSTAT 100, Eco Chemie B.V., Utrecht, The Netherlands) driven by the general purpose electrochemical systems data processing software (voltalab master 4 software) connected to Pentium III computer run under Windows 98. The electrochemical cell contains a HAp-modified carbon paste working electrode, a platinum counter electrode and a saturated calomel reference electrode (SCE). The pH-meter (Radiometer Copenhagen, PHM210, Tacussel, French) was used for adjusting $\mathrm{pH}$ values.

\section{Preparation of the modified electrode Garlic-CPE}

Garlic-modified carbon-paste electrode was prepared according the following procedure [15]. The modified carbon-paste electrode was prepared by mixing the graphite powder with the garlic to give an appropriate ratio Garlic/CP. The mixture was grinding in amortar agate and then a portion of the resulting composite material was housed in PTFE cylinder. The geometric surface area of the working electrode was $0.1256 \mathrm{~cm}^{2}$. A bare of carbon vitreous inserted into carbon paste provided the electrical contact.

\section{Results and Discussion}

The effect of the carbon paste composition in the voltammetric response of the electrode modified with Garlic was evaluated by cyclic voltammetryin $0.10 \mathrm{~mol} \mathrm{~L}^{-1} \mathrm{NaCl}$ media (Figure 1). The anodic peak current increased with the amount of garlic in the paste up to $30 \%(\mathrm{w} / \mathrm{w})$. Beyond the anodic peak current decreased significantly, this probably occurs due to a decrease in the conductive area at the electrode surface (Figure 2). According by these results a carbon-paste composition of $30 \%(\mathrm{w} / \mathrm{w})$ by weights was used in further experiments.

On the cyclic voltammogram recorded on the electrode (30\% Garlic) -CPE (Figure 1), we notice the appearance of a well-defined anodic peak at about $-0.3 \mathrm{~V}$. This peak corresponds to the oxidation of garlic.

\section{Calibration graph of $\mathrm{H}_{2} \mathrm{O}_{2}$}

In this work we chose hydrogen peroxide $\left(\mathrm{H}_{2} \mathrm{O}_{2}\right)$ as a free radical. The reduction of $\mathrm{H}_{2} \mathrm{O}_{2}$ was studied on a carbon paste electrode (CPE) in $0.1 \mathrm{M} \mathrm{NaCl}$ solution by SWV (Figure 3 ). The concentration range of $\mathrm{H}_{2} \mathrm{O}_{2}$ from $4.28 .10^{-2} \mathrm{mmol} / \mathrm{L} \mathrm{NaCl}$ to $0.86 \mathrm{mmol} / \mathrm{L}$ was examined, firstly at CPE. The linear calibration plot (Figure 4) was obtained under optimal conditions. The regression straight line has the following equation:

$\mathrm{iP}=-18.10^{-4} \times\left[\mathrm{H}_{2} \mathrm{O}_{2}\right]+6.10^{-3}$, where $\mathrm{iP}$ is the reduction current density of hydrogen peroxide expressed in $\mathrm{mA} / \mathrm{cm}^{2}$ and the concentration in $\mathrm{mL} / 100 \mathrm{ml} \mathrm{NaCl}$.

*Corresponding author: Abdelilah Chtaini, Equipe d'Electrochimie Moléculaire et Matériaux Inorganiques, Faculté des Sciences et Techniques de Béni Mellal, Université Sultan Moulay Slimane, Morocco, Tel: +212523485112; E-mail: chtainia@yahoo.fr

Received February 26, 2017; Accepted November 23, 2017; Published November 30, 2017

Citation: Saâdane H, Ennachete M, Moutcine A, Qouatli EIS, Chtaini A (2017) INew Electrodes Based on Garlic for the Inhibition of the Free Radicals Effects. Pharm Anal Acta 8: 569. doi: 10.4172/2153-2435.1000569

Copyright: (c) 2017 Saâdane H, et al. This is an open-access article distributed under the terms of the Creative Commons Attribution License, which permits unrestricted use, distribution, and reproduction in any medium, provided the original author and source are credited. 


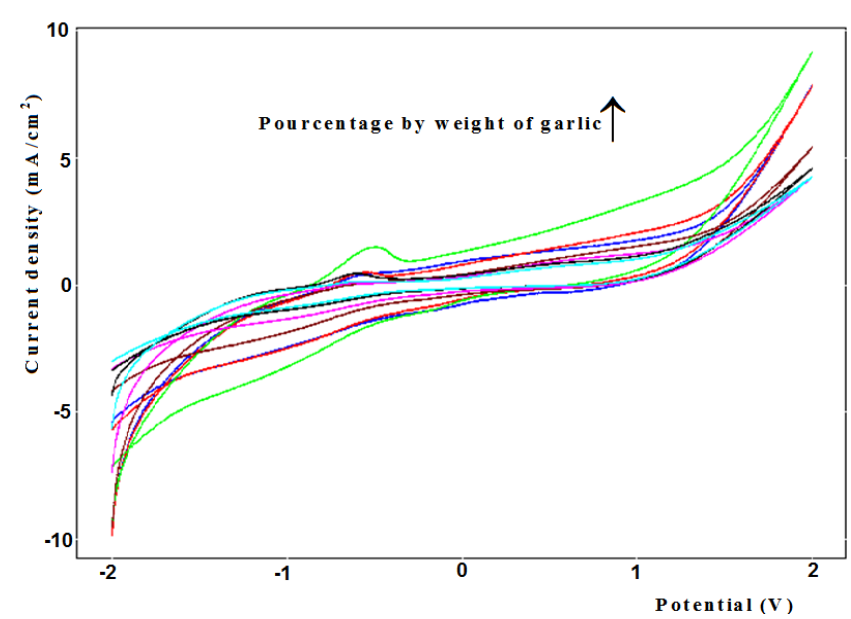

Figure 1: Cyclic voltammograms recorded at Garlic-CPE in $0.1 \mathrm{mlo} / \mathrm{L} \mathrm{NaCl}$ Effect of Garlic content in carbon paste mixture.

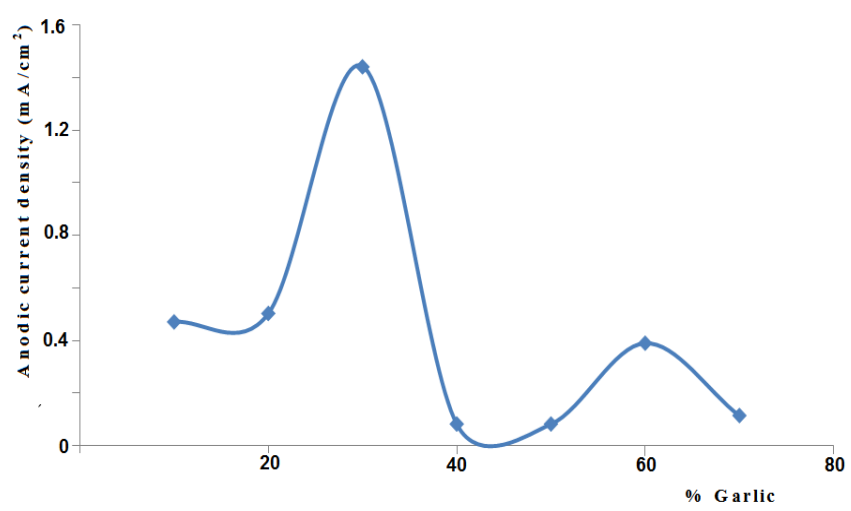

Figure 2: Influence of the content of Galic in carbon-paste mixture $\%(w / w)$ on $\mathrm{CV}$ anodic peak currents density.

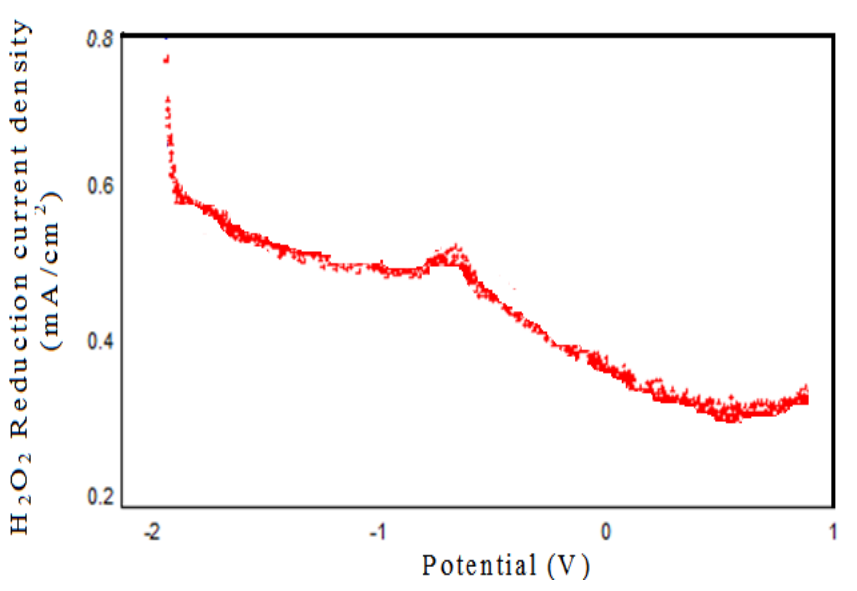

Figure 3: SWV recorded at $\mathrm{CPE}$ in $0.1 \mathrm{M} \mathrm{NaCl}$ containing $0.51 \mathrm{mmol} / \mathrm{L}$ of $\mathrm{H}_{2} \mathrm{O}_{2}$

Figure 5 shows the CVs recorded, respectively on the CPE (curve a) and in CPE modified by $30 \%$ of the garlic, in $0.1 \mathrm{M} \mathrm{NaCl}$ solution. The $\mathrm{CV}$ recorded at $\mathrm{CPE}$ in $0.1 \mathrm{M} \mathrm{NaCl}$ solution containing $\mathrm{H}_{2} \mathrm{O}_{2}$ shows clearly one reduction peak at about $-0.3 \mathrm{~V}$, which corresponds to the following reaction:

$$
2 \mathrm{H}_{2} \mathrm{O}_{2}+2 \mathrm{H}^{+}+2 \mathrm{e}^{-} \rightarrow 4 \mathrm{H}_{2} \mathrm{O}
$$

When the CPE is replaced by the modified gralic/CP electrode, we can see clearly the disappearance of this reduction peak, and thereafter the total stoppage of the reduction reaction of hydrogen peroxide [1]. This leads us to conclude that the presence of the garlic on the matrix of the carbon paste electrode inhibits remarkably the effects of $\mathrm{H}_{2} \mathrm{O}_{2}$.

The same behavior was observed in SWV technique, where we can distinguish the disappearance of the reduction peak of $\mathrm{H}_{2} \mathrm{O}_{2}$, when CPE is replaced by garlic / CPE (Figure 6).

The results of EIS tests are presented through Nyquist diagrams. These diagrams for the CPE (curve a) and garlic/CPE (curve b) surfaces in $0.1 \mathrm{M} \mathrm{NaCl}$ containing $\mathrm{H}_{2} \mathrm{O}_{2}$ are shown in Figure 7. When CPE is CPE is the working electrode, EIS spectra exhibit a half circle in the high-frequency region; it corresponds to the electrochemical reduction of the hydrogen peroxide. Furthermore, this data was changed when $\mathrm{CPE}$ is replaced by garlic/CPE, The half circle disappeared from the diagram, indicating that the reduction reaction of $\mathrm{H}_{2} \mathrm{O}_{2}$ is stopped $[16,17]$.

Figures 8 and 9 shows the evolution of the reduction current density of the $\mathrm{H}_{2} \mathrm{O}_{2}$ as a function of the concentration of the hydrogen

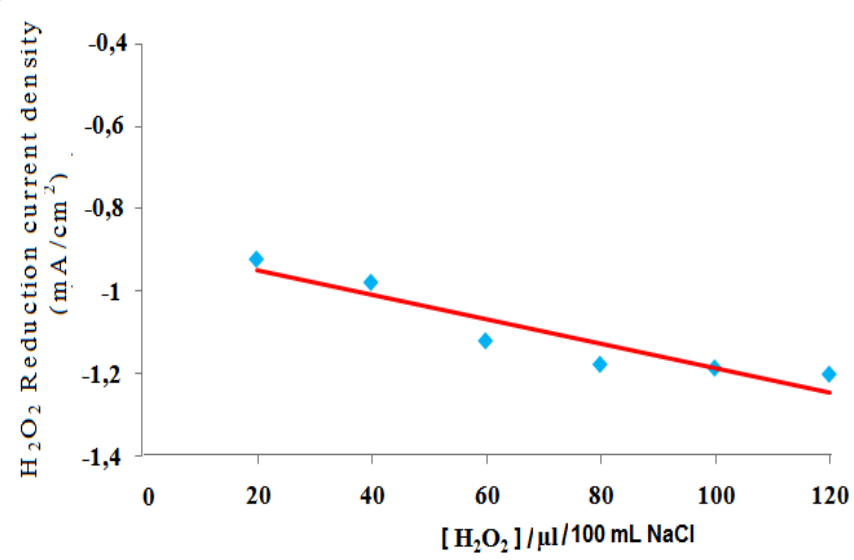

Figure 4: Influence of concentration of hydrogen peroxide on the reduction peaks intensity at CPE under the optimized conditions.

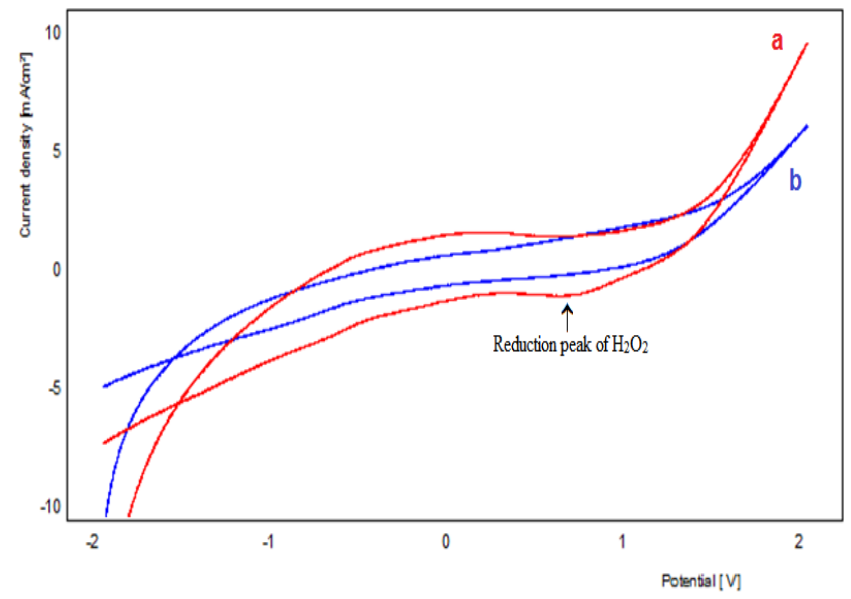

Figure 5: CV's recorded respectively, at a-CPE and b- 30\% garlic/CPE in $0.1 \mathrm{M}$ $\mathrm{NaCl}$ solution containing $\mathrm{H}_{2} \mathrm{O}_{2}$. 


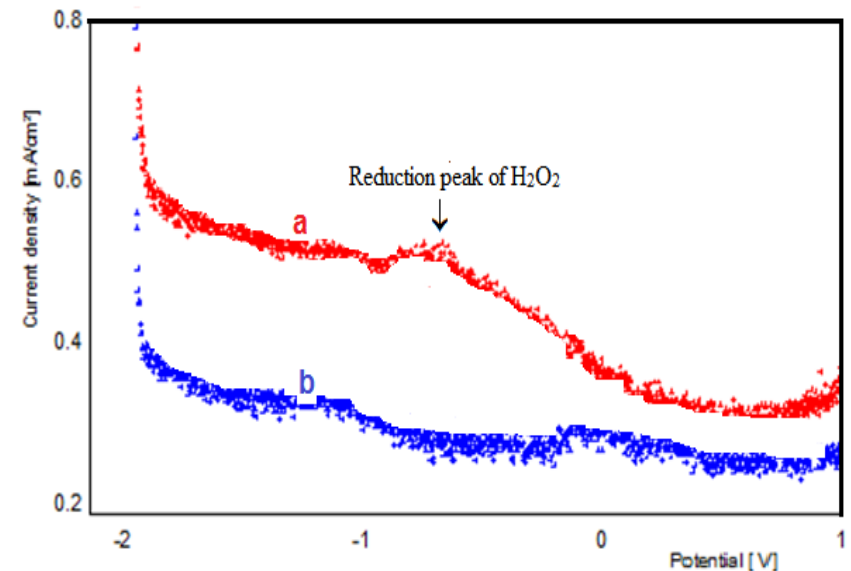

Figure 6: SWV's recorded respectively, at a-CPE and b- 30\% garlic/CPE in $0.1 \mathrm{M} \mathrm{NaCl}$ solution containing $\mathrm{H}_{2} \mathrm{O}_{2}$

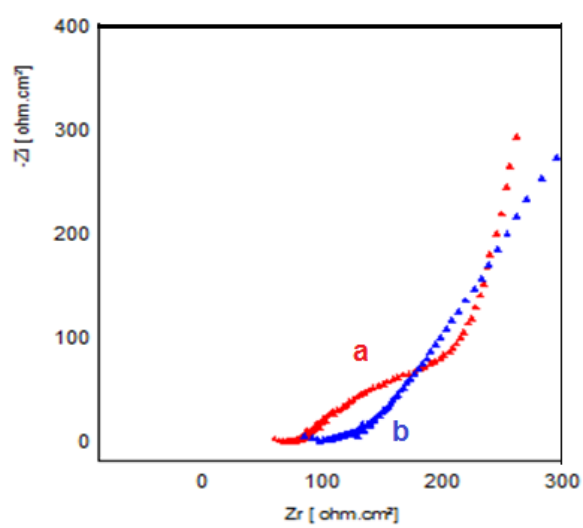

Figure 7: Impedance data recorded respectively on $\mathrm{CPE}$ (curve a) and garlic/ CPE (curve b) in $0.1 \mathrm{M} \mathrm{NaCl}$ containing $\mathrm{H}_{2} \mathrm{O}_{2}$.

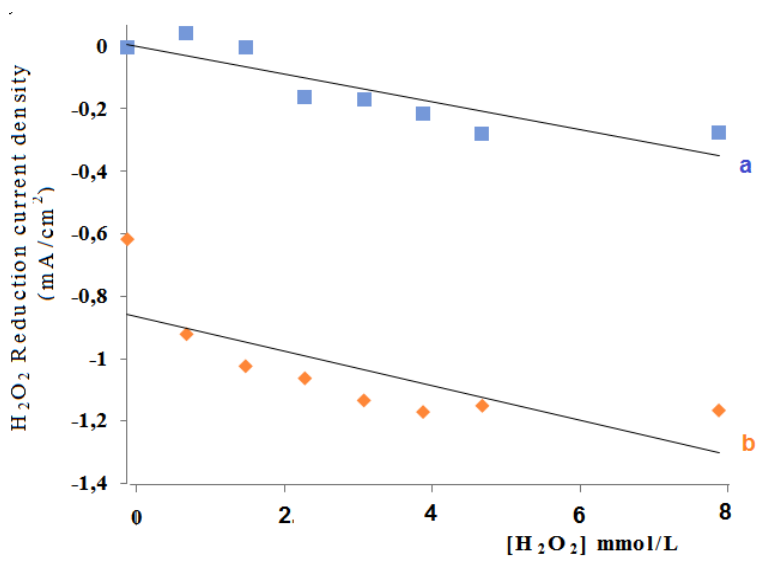

Figure 8: Influence of the hydrogen peroxide concentrations on the reduction peaks intensity, respectively, at: a- Garlic/CPE and b- CPE in $0.1 \mathrm{M} \mathrm{NaCl}$.

peroxide, deduced from the SWV's recorded respectively, on CPE (curve b) and on garlic/CPE (curve a). The presence of the garlic in the matrix of the carbon paste, results in a remarkable drop in the $\mathrm{H}_{2} \mathrm{O}_{2}$ reduction current densities, which exceeds $80 \%$.

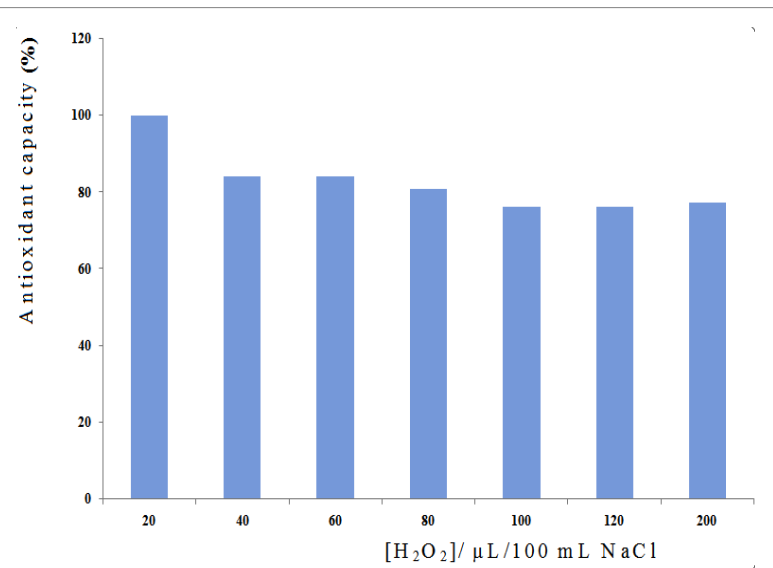

Figure 9: Evolution of the $\mathrm{AOC}$ percentage as function of the hydrogen peroxide concentration

The corresponding antioxidant capacity values (AOC), was calculated using the relation:

$$
\mathrm{AOC}=\frac{\mathrm{J}_{\mathrm{H}_{2} \mathrm{O}_{2}}^{\text {Reduction }}(\mathrm{CPE})-\mathrm{J}_{\mathrm{H}_{2} \mathrm{O}_{2}}^{\text {Reduction }}(\text { Garlic / CPE })}{\mathrm{J}_{\mathrm{H}_{2} \mathrm{O}_{2}}^{\text {Reduction }}(\mathrm{CPE})} \times 100
$$

The results are illustrated by the following histogram:

The antioxidant capacity of the garlic approaches $100 \%$, indicating for the same occasion, that the prepared electrode (garlic/CPE) can totally inhibit the effects of the free radicals.

\section{Conclusion}

For a long time, garlic has been used as an additive in food in various cultures. Garlic is a natural medicine used to treat many diseases, is a powerful stimulant of the immune system. In this work, the garlic was used as a modifier of the carbon paste electrode to inhibit the reduction reaction of hydrogen peroxide often considered a powerful free radical. The composition of the electrode materials that gave the best result is $30 \%$ garlic and $70 \%$ carbon graphite. The antioxidant capacity of the garlic was evaluated, its value exceeding $80 \%$, and its ability to inhibit the $\mathrm{H}_{2} \mathrm{O}_{2}$ reduction reaction may reach $100 \%$.

\section{References}

1. Halliwell B, Gutteridge JMC (2007) Free radicals in biology and medicine. (4 $4^{\text {th }}$ edn). Oxford, UK.

2. Bahorun T, Soobrattee MA, Luximon-Ramma V Aruoma Ol (2006) Free radicals and antioxidants in cardiovascular health and disease. Int $\mathrm{J}$ Med Update 1: 25-41.

3. Valko M, Izakovic M, Mazur M, Rhodes CJ, Telser J (2004) Role of oxygen radicals in DNA damage and cancer incidence. Mol Cell Biochem 266: 37-56.

4. Valko M, Leibfritz D, Moncol J, Cronin MT, Mazur M, et al. (2007) Free radicals and antioxidants in normal physiological functions and human disease. Int $J$ Biochem Cell Biol 39: 44-84.

5. Dröge W (2002) Free radicals in the physiological control of cell function Physiol Rev 82: 47-95.

6. Willcox JK, Ash SL, Catignani GL (2004) Antioxidants and prevention of chronic disease. Crit Rev Food Sci Nutr 44: 275-295.

7. Pacher $P$, Beckman JS, Liaudet $L$ (2007) Nitric oxide and peroxynitrite in health and disease. Physiol Rev 87: 315-424.

8. Genestra M (2007) Oxyl radicals, redox-sensitive signalling cascades and antioxidants. Cell Signal 19: 1807-1819. 
Citation: Saâdane H, Ennachete M, Moutcine A, Qouatli EIS, Chtaini A (2017) INew Electrodes Based on Garlic for the Inhibition of the Free Radicals Effects. Pharm Anal Acta 8: 569. doi: 10.4172/2153-2435.1000569

9. Cervantes MI, de Oca Balderas PM, de Jesús Gutiérrez-Baños J, OrozcoIbarra M, Fernández-Rojas B, et al. (2013) Comparison of antioxidant activity of hydroethanolic fresh and aged garlic extracts and their effects on cerebral ischemia. Food Chem 140: 343-352.

10. Miller HE, Rigelhof F, Marquart L, Prakash A, Kanter M (2000) Antioxidant content of whole grain breakfast cereals, fruits and vegetables. J Am Coll Nutr 19: 312S-319S.

11. Campanella L, Bonanni A, Finotti E, Tomassetti M (2004) Biosensors for determination of total and natural antioxidant capacity of red and white wines: comparison with other spectrophotometric and fluorimetric methods. Biosensors Bioelectronics 19: 641-651.

12. Campanella L, Favero G, Tomassetti M (1999) Superoxide Dismutase biosensors for superoxide radical analysis. Analytica Lett 32: 2559-2581.
13. Bonanni A, Campanella L, Gatta T, Gregori E, Tomassetti M (2007) Evaluation of the antioxidant and prooxidant properties of several commercial dry spices by different analytical methods. Food Chem 102: 751-758.

14. Mello LD, Kubota LT (2007) Biosensors as a tool for the antioxidant status evaluation. Talanta 72: 335-348.

15. El Mhammedi MA, Bakasse M, Chtaini A (2007) Square-Wave Voltammetric Determination of Paraquat at Carbon Paste Electrode Modified with Hydroxyapatite. Electroanalysis 19: 1727-1733.

16. Liu Y, Liu X, Guo Z, Hu Z, Xue Z, et al. (2017) Horseradish peroxidase supported on porous graphene as a novel sensing platform for detection of hydrogen peroxide in living cells sensitively. Biosensors Bioelectronics 87: 101-107.

17. Chen W, Cai S, Ren QQ, Wen W, Zhao YD (2012) Recent advances in electrochemical sensing for hydrogen peroxide: a review. Analyst 137: 49-58. 